\title{
Discourses about Daily Activity Contracts: A Ground for Children's Participation?
}

\author{
Roberta Bosisio *(D) and Manuela Olagnero
}

Department of Culture, Politics and Society, University of Turin, 10153 Torino, Italy; manuela.olagnero@unito.it

Received: 19 November 2018; Accepted: 4 March 2019; Published: 11 March 2019

check for updates

\begin{abstract}
The paper presents the findings of a secondary analysis of qualitative research conducted in Turin (Northern Italy) in 2012-2013 on autonomy and responsibility in the relationships between children and parents. A total of 46 parents and 48 children aged 9-13 were interviewed. The secondary analysis focuses on a specific section of the in-depth interview dealing with daily activity contracts. The aim is to investigate children's participation in everyday life through children's and parents' narratives about daily activity contracts. Thematic analysis of this section of the interviews shows that children make room for acquiring such relational and dialogue skills as self-confidence and speaking up, which are recognized to be essential for any level and type of participation. Moreover, children's and parents' discourses on daily activity contracts provide an opportunity to "cultivate" participation and autonomy through a sort of alliance between parents and children in decision-making. The question is whether these dialogic attitudes and negotiation abilities are a resource not restricted to the family sphere but which extends to other areas of participation that go beyond the realm of private, protected, and reversible choices .
\end{abstract}

Keywords: children's participation; generational relations; family change; daily activity contracts

\section{Introduction: Participation as a Polysemic Concept}

The aim of this paper is to investigate children's participation in everyday life through children's and parents' narratives about daily activities. This purpose cannot be addressed without illustrating the ongoing debate on children's participation and the meaning assigned to it against the backdrop of changing generational relationships.

Children's participation rights-together with rights to protection and provision-are among the fundamental rights recognized by the 1989 Convention on the Rights of the Child (CRC). The CRC's introduction of participation rights was an innovation, as adults were called upon not only to protect children and provide them with all the resources, opportunities, and instruments needed to promote their development and well-being, but also to recognize them as persons having the right to be involved together with adults in the decisions that affect them and their well-being.

Article 12 of the CRC states that "Parties shall assure to the child who is capable of forming his or her own views the right to express those views freely in all matters affecting the child, the views of the child being given due weight in accordance with the age and maturity of the child". This entails exercising a range of other subjective rights enshrined in the CRC such as freedom of expression (Art. 13); freedom of thought, conscience, and religion (Art. 14); freedom of association (Art. 15); and privacy (Art. 16). These rights give children the power to express their views, display preferences, receive and provide information, etc., that should lead to various forms of participation in both social and political life (Baraldi and Iervese 2012; Olagnero and Rei 2011).

Participation is indeed a multifaceted concept and, for this reason, is at the center of debates and subject to continuous redefinition, re-conceptualization, and critique (Wyness 2015; Thomas 2007).

Participation includes the following: 
(a) Actions ranging from simply taking part or being consulted (simple agency Giddens 1984) to contributing to decisions (taking part in the decision-making process, or agency). The emphasis is on the process in the first case and on the outcome in the second (Thomas 2007).

(b) Actions involving both collective decision-making and decisions about children's individual lives (Thomas 2007). These actions take place in two different contexts: first, that of public institutions (schools, communities, local administrations) that have to do with civic and political participation and whose mission should guarantee public engagement, responsibility, and solidarity. The second context of action lies in children's own spaces of freedom and choice in the family, at school, and in leisure time.

Notwithstanding the ambiguity and criticisms surrounding the meaning and implementation of children's participation and participation rights,

(a) Participation is one of the most widely investigated issues relating to the CRC in academia (Reynaert et al. 2009).

(b) Participation and participation rights have become essential to ensuring children's well-being, so much so that participation has been included among the indicators used to compare children's well-being at the international level (Olagnero 2016)

(c) Lastly, introducing the principle of participation in discourses of children's rights has contributed to changing generational relationships. In fact, it has promoted greater symmetry of the roles in these relationships, encouraging greater democratization of decision-making (Pocar and Ronfani 2008; Giddens 1992; Baraldi and Cockburn 2018).

\section{The Context of the Research: Participation and Intergenerational Relationships}

A number of scholars dealing with children's participation have stressed the centrality of adult-child relations, pointing out that individuals (both children and adults) are embedded in a network of relationships (Moss and Petrie 2002). As a consequence, participation must be conceptualized in relational terms. Scholars sharing this approach emphasize that the idea of children as competent social actors, if taken to the extreme, runs the risk of viewing childhood as an "essentialised category" (Prout 2011, p. 1). An "over-emphasis on the notion of the child as agent" (Horgan et al. 2017, p. 276) may neglect or underestimate the complexity of children's lives (Oswell 2013) and the role played by adults (Fielding 2007). As early as 2001, Alanen (2001) noted that childhood is the product of children's and adults' co-construction in their network of intergenerational and peer relationships, located in specific socioeconomic and cultural settings, while the same can be said of their experiences of participation (Kjørholt 2007). In this connection, Fielding (2007, p. 304) argues that children's participation emerges out of "dialogue" and "intergenerational engagement"; it thus goes beyond consultation and listening to their opinions to include "more child-initiated practices" reflecting different kinds of intergenerational relationships (Wyness 2016).

Several authors maintain that intergenerational relationships inevitably involve a question of power. According to Baraldi and Cockburn (2018, pp. 10-12), for example, "a generational order implies the capillary exercise of power in adult-children relations and the discipline of children's lived citizenship." In hierarchical structures, children's participation thus appears mostly as simple agency and is subordinated to adults' authority.

Other scholars argue that the cultural and social changes in the family domain that are now occurring in Western cultures relax the hierarchical order and allow children to practice their agency through dialogue (Pocar and Ronfani 2008). Parenting is a two-way process of teaching and learning, in which the lessons learned are re-interpreted by children and-it might be added-in turn, influence parents, thus furthering mutual learning (Bosisio 2010).

At the same time, however, it is emphasized that putting these principles into practice and turning them into rules of conduct is difficult and calls for a "process of metabolization" that is perhaps still underway (Belloni 2016, p. 7). 
This ongoing process has brought about a number of changes (Vandenbroeck and Bie 2006; Wingard 2007), namely,

(a) There is less inclination to look ahead (the longest horizon is the next year).

(b) Parents' experience has become obsolete (no formula such as "when I was ... ").

(c) There are no commands or punishments, as everything is agreed/negotiated in advance.

(d) There is no direct or firm opposition between generations: "my mother could be right" (end of intergenerational conflict).

(e) Directives are mitigated or downgraded (collaborative we-forms).

(f) Rules and procedures take precedence over values (Solberg 1997; Sarre 2010).

In Italy today we can observe contrasting trends in children's upbringing. On the one hand, parents are very aware of the importance of acquiring competences that can be seen as essential prerequisites for autonomy: "it is always too late/already late!" (to learn English, to play the piano, to take up a sport, to be independent in mobility and social relations) (Bonica and Olagnero 2011; Olagnero 2006). This has the effect of "adultizing" children.

On the other hand, families are aware of the possible dangers and disadvantages of growing up too fast: "it's too early!" (to choose a course of study, to quit school, to take a job, to be left alone or unsupported), hence the commitment to keeping children at a safe distance from the dangerous world of adults ("Let children be children!"). Likewise, children are aware of their moral status and competence but also internalize the need to be increasingly protected from the greater dangers of the adult world (Holland et al. 2000).

One attempt to overcome the ambivalences of parenting consists of the professionalization of child-rearing practices: parents call for different adult voices and actors, in addition to teachers, to be involved in children's everyday upbringing (specialists in education and pedagogy, trainers in sports and organized leisure activities, psychologists, etc.). The great variety of professional figures supporting parents, each with different commitments to and representations of the child's well-being, contributes to decentralizing parental responsibility but also to increasing the complexity of the role taken by parents compared with those of the other adults involved in children's upbringing (Satta 2012).

Parents' desire to provide effective protection from future risks while still promoting opportunities often results in intensive parenting (Gómez Espino 2013). However, intensive parenting also shows ambiguities and inconsistencies. For example, children who are allowed independence are not always assigned responsibility (Mayall 2002), which remains with the parents together with the uncertainties about their role in children's upbringing. In the traditional view, as children's decision-making skills improve with their autonomy, so does their assumption of responsibility. At the same time, there are fewer reasons for parents to be responsible for their children. On the contrary, there is now good reason to question the positive correlation between autonomy and responsibility. In specific circumstances, parents are responsible for events and outcomes related to children's autonomy (Hartvigsson and Munthe 2018).

In this respect, discourses about daily activities and the rules relating to autonomy and responsibility provide a useful observatory for investigating children's participation in social life. Indeed, daily activities describe actions that are not isolated but are organic parts of a specific cultural pattern driving intergenerational relationships.

\section{The Analytical Framework: Parenting Styles}

To illustrate children's ability to participate together with their parents in everyday life, we carried out a secondary analysis of discourses about children's daily activities recorded in research conducted in Turin (Northern Italy) in 2012-2013. This research on autonomy and responsibility in the relationships between children and parents was part of the national project entitled Responsibility 
in family relations: practices and norms, explanations and representations, funded by the Italian Ministry of Universities and Research (Protocol 2008FB7KE5) (Maggioni et al. 2013).

The study involved 46 couples-born between the 1960s and 1970s and who became parents between 1995 and 2000-and their 48 children aged 9-13 (two couples had two children of this age). The participants, most of whom were of medium-high socioeconomic status, were recruited through the two primary and middle schools attended by the children. Both parents and children were interviewed separately and in depth at home. Only four fathers out of the 46 participating couples agreed to be interviewed. This could confirm that in Italy, mothers still bear most of the responsibility for children's upbringing even in highly educated, double-income families.

Although the study also involved teachers in focus groups, only data from interviews with children and parents were used for this paper. For our purposes here, it is sufficient to say that the findings from the focus groups with teachers confirmed the loss of the so-called social distance between parents and children, indicating that it also extends to the relations between teachers and pupils, paralleling those between adults and children in the various social environments (Belloni 2016).

In accordance with Italian Law 391/2006, all participants were asked to provide their consent to take part in the research. Parental consent was obtained for the children, who were informed that they could choose freely whether or not to participate.

The data highlighted four parenting styles (Torrioni 2013, pp. 93, 95) that roughly reflect the typology of parenting developed by Baumrind $(1966,1971,1996)$. These styles were identified on the basis of two dimensions:

(a) Parents' expectations: promotion of children's self-realization and self-control on the one hand, and hetero-regulation and obedience on the other.

(b) Systems of rules adopted by parents: implicit and de-structured versus explicit and structured.

The parenting styles are as follows (Table 1):

(a) The negotiation style: Parents aim to develop self-realization and self-control in children through reciprocity, exchange, and sharing; rules are explicit and can be questioned under certain conditions.

(b) The permissive style: Parents aim to indulge children's wishes unconditionally; rules are flexible and can be suspended.

(c) The ambivalent style: Parents' aim oscillates between protection and promotion; rules are not explicit, but loose, contingent, and subject to exceptions.

(d) The authoritarian style: Parents' aim is to obtain obedience and exert control; rules are clear and explicit.

Table 1. Parenting styles.

\begin{tabular}{ccc}
\hline \multirow{2}{*}{ System of Rules } & \multicolumn{2}{c}{ Parents' Expectations } \\
\cline { 2 - 3 } & Self-Direction & Obedience \\
\hline Explicit & negotiation style & authoritarian style \\
\hline Implicit & permissive style & ambivalent style \\
\hline & Source: based on Torrioni (2013, p. 95).
\end{tabular}

The parenting styles that emerged most frequently from the study were the permissive (20 cases) and the negotiation styles (13 cases). The remaining cases involved the ambivalent style (7) and the authoritarian style (6).

At least from an analytical standpoint, three out of the four parenting styles are dialogic and include different levels of children's participation: in various ways, children have the opportunity to have a say and for their opinion to be given due consideration, and at times they can also take part in decision-making processes. 


\section{Theory and Method: Parents' and Children's Narratives about Daily Activities}

In the secondary analysis presented in this paper, the typology outlined above was used to interpret the narrative between parents and children in the light of the concept of daily activity contracts concerning organized leisure activities and sports.

As a recent study has documented, parents engage in what have been called activity contracts, i.e., promises about future action as a way of securing children's compliance. Activity contracts thus involve the child's future actions and moral accountability (Aronsson and Cekaite 2011). In (time) negotiation, both parents and children back up their positions by explaining, justifying, and excusing themselves as moral persons (Aronsson 2018, p. 50)

The analysis assumes that the family's prevalent parenting style shapes the generational dialogue between parents and children about daily activities. Daily dialogue structures children's discursive abilities: exploring children's representations of interactions in everyday life allows the researcher to interpret their experience in terms of "sense-making" and "life world"-(Ulvik and Gulbrandsen 2015); narrative form is "an important part of documentation of children's experiences and their understanding of the interactions in which they are involved" (Aronsson et al. 2018, p. 6).

It should be also emphasized that the children involved in the study were in a particularly crucial period of life. The passage from primary to secondary school during preadolescence is of acknowledged importance to children's acquisition of greater opportunities for independence, responsibility, and competence, for example, in being able to move on their own and choose free-time activities (Bosisio 2010).

From the methodological standpoint,

(a) interviewing children in these age groups about their representations of daily activity contracts (timing, sequence, rules, actors involved) reduces the power imbalance between adults and children and thus avoids the risk that children's responses will be affected by shyness, self-censorship, or compliance with adults' expectations (Olagnero 2013).

(b) Daily life routines generate competence and reinforce the idea that everyone contributes to managing the household and thus make children self-confident about their place in intergenerational relationships (Aronsson and Cekaite 2011).

(c) Moreover, narrating daily activity contracts allows children's discursive ability to emerge. We regard this ability as the first step for children's participation in social life. "The dynamic appropriation of the available repertoire (of talks and words) that positions the voice of the speaker-writer is called languaging. Children are fully capable of languaging activity which positions them socially" (Cortese 2011, p. 13). Language's importance is also emphasized by cultural psychology (Vygotsky 1998; Bruner 1990), which maintains that it is not only a means of communication but also a tool for meaning-making and identity construction.

(d) As the parents' narratives contribute to the co-construction of discursive abilities, they are included in the analysis. The narratives of children and parents can be considered "conversations from a distance", given that even if children and parents do not speak directly, their narratives regarding children's daily activities are closely intertwined: both speak of common issues that concern them personally and where their relational approaches are displayed. Moreover, involving parents and recording their narratives as well, juxtaposing parents' statements with those of children, makes it possible to adopt several interpretive assumptions of what Riessman (2003) calls "dialogic/performance analysis". In this regard, the epistemologist Bakhtin, cited in Riessman, says that in narrative "form and meaning emerge between people in social and historical particularity in a dialogic environment" (Riessman 2003, p. 107).

To conduct the interviews, two interview guides were developed: one for the parents and one for the children. The questions contained in the specific section on daily activities investigated (a) choice and commitment in organized leisure activities and sports and (b) rules, punishments, autonomy, and responsibility in daily life. 
The interviews were audio-taped, transcribed verbatim, and thematically analyzed.

\section{Findings and Discussion: Children's Discursive Abilities and Participation}

Several excerpts were selected from the interviews with parents and children belonging to 10 families classified according to the parenting styles presented in Section 3.

In the excerpts the families are identified with the names of flowers (Sunflower, Artemisia, Snowdrop, Begonia, Gardenia, Dogwood, Primrose, Gentian, Amaryllis, and Tea Rose). Except for one family, in which both parents were involved, the parents' narratives are those of the mothers (Table 2).

Table 2. Families by parenting styles.

\begin{tabular}{cc}
\hline Parenting Style & Families \\
\hline negotiation style & Sunflower, Artemisia \\
\hline authoritarian style & Snowdrop, Begonia \\
\hline permissive style & Gardenia, Dogwood, Primrose \\
\hline ambivalent style & Gentian, Amaryllis, Tea Rose \\
\hline
\end{tabular}

Two topics were identified for the analysis:

(a) Autonomy, responsibility, and rules in daily life activities.

(b) Commitments in sports and organized leisure activities.

These topics can shed light on how the different parenting styles work in the discourses of both parents and children.

The first two excerpts refer to the ways parents who adopt the ambivalent style define autonomy and responsibility. In the first, the idea of a prolonged childhood is such that mother Amaryllis comes to question the borders between children and adults:

[... ] well, I think it's hard to find a child of this age who's independent and responsible; if they were, they'd already be adults, and sometimes even we aren't very adult ourselves. (mother Amaryllis, son at middle school, ambivalent)

During the interview, both Amaryllis parents mention the disagreements between them regarding the child's upbringing, hence the father's idea that too many rules and punishments are harmful, since he cannot enforce them:

[... ] I often find that my wife is too rule-bound, too insistent about certain demands or punishments, and so we don't always agree about whether to make him do whatever it is ... uhm. A lot of times, she threatens to punish him and then doesn't follow through on it, uhm ... and vice versa, and so we can't even expect him to take models of a certain kind when we're the ones who start creating confusion for him in general, uhm. (father Amaryllis, ambivalent)

Mother Gentian, another example of the ambivalent parenting style, reveals the unavoidable contradictions of applying rules when a number of stimuli are involved. For parents as well as children, applying the rules, in fact, means dealing with the consequences.

[... ] There are so many stimuli, I mean, "No more TV for you!" you go to the computer, and so, "No more Internet for you" but you find something else; at the end either you shut them in a cage or things get turned around pretty quickly anyway... One of the issues we're talking about is taking away things that are important, and so "no more dance, no more skiing, you're not going on vacation!" So. [ ... ] Uhm Because they're never very feasible, in the sense that if I don't let you go on vacation, I can't go either. (mother Gentian, daughter at middle school, ambivalent) 
With uncertainty like this, children reassure their parents about their capacity for self-discipline and ability to manage time independently, as adults do:

[... IIf they were to put limits on something, I'd say they ought to put limits on the computer, but they don't do that because they know I'd never go to the computer unless I knew I had something to do urgently ... I go to the computer when I'm relaxed, not when I've finished all my homework ... but if there's something for Friday and it's only Wednesday, I say: "OK, I've already worked for two hours, I know I'll do it ... on the [due] day, I'll do it ... " (daughter Gentian, middle school, ambivalent)

Other primary and middle schoolchildren are conscious of the contradictions of parental rules, be they implicit or explicit:

[... ] My mother [if and when the speaker forgets to do a homework assignment] always threatens not to give me my allowance [smiles] or my father says ... that I'll find my bed stripped ... and then every evening I find everything OK. [laughs] (daughter Sunflower, middle school, negotiation)

Parents do not always have the answer to everything. When in doubt, they attempt to shift responsibility onto the other parent. Even the smallest children realize that this result is in an impasse:

[ ... ] My father always says: "ask your mother" because he doesn't know what to answer, whether to say yes or no; and so he always says "go ask your mother"; my mother says: "ask your father" and so I say: "should I ask grandma?" (daughter Dogwood, primary school, permissive)

The authoritarian parents also believe that rules do exist, but they cannot always be complied with absolutely:

[... I I always tell him he's got to do his homework, it's his duty; obviously there are times when maybe he's a bit slack about it ... he's pretty good about listening to what I say, he's pretty good about following the rules, so I don't feel I have to dole out a lot of punishment. (mother Begonia, son at primary school, authoritarian)

Children clearly notice the differences in parenting styles between families. This can give them the idea that the rules are relative:

[... ] My parents say that I can do whatever I want, but without going to extremes. Parents of a schoolmate of mine have lots of rules, written on the wall ... Compared with my classmates, I feel a bit strange, I don't understand why my parents don't do that or even why that mother does. (daughter Primrose, primary school, permissive)

Several examples follow of how the uncertainty disappears when these kinds of daily activities are at stake.

Both parents and children share the feeling that extracurricular activities are a necessary part of the daily agenda. Even in the words of the most permissive parents, these activities are often referred to in the imperative, as something that "has to" be done:

[...] She knows she has to play the violin for an hour or so, the piano for half an hour, half an hour practicing sight reading. She knows she has to do it. (mother Gardenia, daughter at middle school, permissive)

For their part, children do not think of these activities as duties, but as something they like to do:

[... ] And so ... I play the violin, I like music a lot ... I've got a really good ear ... and ever since I was really, really small I've liked opera a lot ... (daughter Gardenia, middle school, permissive)

Sports are another matter, as both parents and children see them as essential, not just to be healthy, but also as a way to prevent laziness and isolation.

Mother Artemisia, aware of her son's laziness and his need for exercise and companionship, talks about how she convinced him to take up track and field. 
[... ] [I told him] So as not to just sit around doing absolutely nothing, let's try doing something different, and he liked it. (mother Artemisia, son at middle school, permissive)

This is how her son represents the situation:

[ ... ] I've got to do sports; I mean, it's not that I've got to, but anyway, you always need to do some sports so as not to be on the couch all the time watching TV. (son Artemisia, middle school, permissive)

Parents who adopt an authoritarian parenting style use moral suasion to get their children to accept the compromises they propose. The children accept the rules with the proviso that they can quit and do something else if a sport is not to their liking.

The authoritarian parenting style seems to be characterized more by patience in insisting on a proposal than on a rigid adherence to rules.

[...] We chose swimming for him... so that he would learn. He would have wanted to play soccer, and then we chose judo, but he didn't object. (mother Snowdrop, son at primary school, authoritarian)

[...] [I'm] on the swimming team because mommy decided on it, because she wanted me to learn to swim ... I'm not very good at it. [I do] judo because I like it. I wanted to play soccer, mommy told me "Maybe next year". (son Snowdrop, primary school)

[ ... ] He chose karate himself. We, we advised him to do it. He took a trial lesson, liked it, and started; when he wanted to quit, he quit ... (mother Begonia, son at primary school, authoritarian)

[... ] At the beginning I didn't want to go [to karate]. I started crying, then I came out of class: my father took me ... to the gym, eh and so I said I'll try it. I got home, I still hadn't made up my mind, and then I convinced myself. I went, I liked it; I got as far as my brown belt and then I quit. (son Begonia, primary school, authoritarian)

The following excerpts are from a relevant "conversation from a distance" between a mother and her son. They are talking about the activity contract of swimming. The child has stopped swimming against his mother's will, but he is also willing to take a cautious step back. She persuades her son to try out the various possibilities, signaling her involvement ("let's have a go"). She also expects that her son will give up, but does not plan to punish him. This possibility is presented as something to be taken in stride ("if they say "we can't do it", it's not as if I kill them").

[... the tendency is to try for a whole year, then at the end of the school year ... if they're the ones who tell me "we can't do it", it's not as if I kill them, you know, you try. When E. told me, "but maybe we'll suspend the swimming", because it was just too much at that point, we shelved the swimming and started to try with volleyball. Just to see. But then he was the one who went to say that he wanted to continue [swimming]. (mother Tea Rose, son at middle school, ambivalent)

The son reconstructs the situation as it evolved, showing that he himself changed his mind. He masters his mother's way of speaking, reporting his mother's words in their dialogue on the pros and cons of a physical activity. The words in the excerpt belong to a repertoire that can be assumed to be shared by both children and adults. Like an adult, in fact, the boy is willing to reconsider the validity of his mother's arguments in the future. In particular, it should be noted that the boy's use of the expression "providing that" is typical of adult argument:

[...] At the beginning I didn't want to. My mother wasn't very happy about it because it was something that meant a lot to her ... when, say, there were sad days, grey, rainy, cold, she'd say: "Try! Come on, go to the pool, there anyway you'll all warm up, get moving, get rid of all the extra energy!". At the beginning I'd say: "No, but what a drag! Wouldn't it be better to stay at home without all that fuss?" But in fact then when you'd get into the pool you'd feel better ... 
And he adds

[...] maybe next year I'll reconsider it [swimming], actually. I really think I'll start again, I really miss it, providing that it jibes with my other commitments. (son Tea Rose, middle school, ambivalent)

In this narrative's timeframe, the boy's ideas about what he does and doesn't want to do, and the fact that he changes his mind, all make sense. It is also interesting to note that even if parents and children are not speaking directly to each other, their statements make explicit mention of the exact words contained in their daily conversations.

Parents whose styles are classified as ambivalent and permissive differ from those with negotiation and authoritarian styles in a further respect, in addition to those contemplated by the classification: their willingness to call themselves and their parenting abilities into question.

Aside from parenting style, the challenge of daily activity contracts lies above all in being able to balance different interests and kinds of intense, prolonged commitment. Negotiations between parents and children hinge on whether the latter can interrupt what they started.

\section{Discussion}

Overall, the secondary analysis indicates that the discourses of both children and parents reflect the current changes in generational relationships in everyday life outlined above: dialogue is a pervasive feature of intergenerational encounters in daily activity contracts. This finding confirms that negotiation is one of the main ways in which children and adults engage in dialogue and that, at times, it involves mutual apprenticeship (Aronsson and Gottzén 2011).

The thematic analysis brought several points to light. For example, parents have substantial difficulty in laying down absolute rules, while children demand autonomy and responsibility only in certain areas. Children and parents tend to agree on the value of a day full of commitments: children have a full agenda organized together with their parents (Cavaletto and Olagnero 2013). In all of the parenting styles, there is an emphasis on promoting or, in other words, on cultivating the children's talents and preferences. As Lareau (2002) notes, middle-class parents in particular express this desire to promote by pressuring children to acquire extracurricular skills through organized leisure activities. Lareau calls this practice "concerted cultivation".

The analysis also shows that families make room for children to acquire such relational and dialogue skills as self-confidence and speaking up, which are recognized to be essential for any level and type of participation.

Children seem to help their parents shake off doubts and uncertainties. Paradoxically, in fact, parents seek their children's confirmation in loosening the knots that tie them to indecision. For children, daily life thus appears to be an occasion for reflecting both on themselves and on adulthood with its difficulties and contradictions.

From this perspective, children's and parents' discourses on daily activity would appear to point to a sort of alliance in decision-making. The narrative core of these discourses often centers on how to deal frictionlessly with daily activity contracts concerning organized leisure activities (practicing a sport, learning to play an instrument, etc.) when complications arise. The appearance of a complicating event, the pivotal ingredient in any story (Labov 1982), gives children the opportunity to learn to defend their choices and also to obtain their parents' consent.

The shift in child-adult relations entails changes in adulthood as well as childhood. As Lee (2001, pp. 7-8) states, in an era defined by permanent flux, it is not just that children are no longer "incomplete adults", adulthood has been divested of the mantle of completeness. Ulrich Beck has suggested that the disappearance of "goals or certainties that must be 'inoculated into' young people" means that the transition to adulthood "is now possible only through 'self-socialization"” (Beck 1998, p. 163).

Self-socialization in turn implies discursive capacities. The interviewed children demonstrate a widespread capacity for languaging, regardless of their gender and age. This capacity consists not 
only of being able to reproduce their parents' linguistic repertoire but also of using it to support their own ideas, distancing themselves when necessary from the adults' standpoint. In an exemplary ethnographic study conducted in the USA in the early 2000s, Annette Lareau interpreted this reflexive attitude in terms of social class: "middle class parents ( . . ) stress language use and the development of reasoning and employ talking as their preferred form of discipline" (Lareau 2002, p. 748). But, as Lareau tells us, while "concerted cultivation" creates a wealth of experience, it can also encourage self-centering attitudes and fuel a cult of individualism.

\section{Conclusions}

In research with participants of medium-high socioeconomic status in an urban area of north-western Italy, analysis of children's and parents' discourses about daily activity contracts shows that children's participation is closely interwoven with the role played by parents who, because of the current uncertainty surrounding the parental mandate, seem to join their children in exploring the most appropriate strategies for helping children participate and practice their agency.

For children, their parents' uncertainty is an opportunity rather than a limit to participation, and it also gives them the chance to "occupy" a discursive and decisional space that would otherwise be denied them.

However, this opportunity also raises an important question: can these dialogic, discursive, and negotiation abilities, which are increasingly important given the current level of social and economic competition, constitute a resource outside the sphere of self-realization and extend to other areas of participation that go beyond the realm of private, protected, and reversible choices?

Author Contributions: Although the paper is the outcome of the joint reflection of the authors, R.B. wrote Sections 1-3, M.O. Sections 3-6, both authors wrote Section 7. Conceptualization, both authors; Data curation, author M.O.; Formal analysis, both authors; Investigation, author M.O.; Methodology, both authors; Writing-original draft, R.B. wrote Sections 1-3 and 7; M.O. wrote Sections 4-6; Writing-review and editing, both authors.

Funding: The research was part of the nationwide project entitled Responsibility in Family Relations: Practices and Norms, Explanations and Representations funded by the Italian Ministry of University and Research (Protocol 2008FB7KE5). The findings have been published in Belloni (2013), and Maggioni et al. (2013).

Conflicts of Interest: The authors declare no conflict of interest.

\section{References}

Alanen, Leena. 2001. Childhood as a Generational Condition: Children's Daily Life in a Central Finland Town. In Conceptualising Child-adult Relations. Edited by Leena Alanen and Berry Mayall. London: Palmer Press.

Aronsson, Karin. 2018. Daily Practices and the Time Politics of Family Life. In Children, Childhood and Everyday Life. Edited by Marianne Hedegard, Karin Aronsson, Charlotte Højholt and Oddbjorg Ulvik. Charlotte: IAP.

Aronsson, Karin, and Asta Cekaite. 2011. Activity Contracts and Directives in Everyday Family Politics. Discourse and Society 2: 137-54. [CrossRef]

Aronsson, Karin, and Lucas Gottzén. 2011. Generational Positions at a Family Dinner: Food Morality and Social Order. Language in Society, 405-26. [CrossRef]

Aronsson, Karin, Marianne Hedegaard, Charlotte Hoihølt, and Oddbjørg Skjær Ulvik. 2018. Rethinking Development: Situated Studies of Children's Perspectives. In Children, Childhood and Everyday Life: Children's Perspectives, 2nd ed. Edited by Marianne Hedegaard, Charlotte Hoihølt and Oddbjørg Skjær. Ulvik: IAP.

Baraldi, Claudio, and Tom Cockburn. 2018. Introduction: Lived Citizenship, Rights and Participation in Contemporary Europe. In Theorising Childhood. Citizenship, Rights and Participation. Edited by Claudio Baraldi and Tom Cockburn. Basingstoke: Plagrave Macmillan.

Baraldi, Claudio, and Vittorio Iervese. 2012. Participation, Facilitation and Mediation. Children and Young People in their Social Contexts. New York: Routledge.

Baumrind, Diana. 1966. Effects of Authoritative Parental Control on Child Behavior. Child Development 4: 887-907. [CrossRef] 
Baumrind, Diana. 1971. Current Patterns of Parental Authority. Developmental Psychology Monograph 1: 1-103. [CrossRef]

Baumrind, Diana. 1996. The Discipline Controversy Revisited. Family Relations 45: 405-14. [CrossRef]

Beck, Ulrich. 1998. Democratization of the family. Childhood 4: 151-68. [CrossRef]

Belloni, Carmen ed. 2013. Transizioni. Bambini e adulti nella società dell'incertezza. Roma: Carocci.

Belloni, Maria Carmen. 2016. Talking about Childhood Today. Participation, Rights and Well-being. Some First Thoughts. In Becoming Children. Well-Being, Participation, Citizenship. Edited by Maria Carmen Belloni, Roberta Bosisio and Manuela Olagnero. Torino: Accademia University Press.

Bosisio, Roberta. 2010. Bambini e Agire Morale. Milano: Guerini.

Bonica, Laura, and Manuela Olagnero. 2011. Come va la scuola? Famiglie e genitori di fronte a scelte e carriere scolastiche. Roma: Infantiae.org.

Bruner, Jerome. 1990. Acts of Meaning. Cambridge: Harvard University Press.

Cavaletto, Giulia Maria, and Manuela Olagnero. 2013. “Che cosa vuoi fare?". I discorsi tra genitori e figli sulle scelte della vita quotidiana. Minorigiustizia 3: 26-35. [CrossRef]

Cortese, Giuseppina. 2011. Introduction. In Reflections on Children's Rights. Marginalized Identities in the Discourses(s) of Justice. Edited by Giuseppina Cortese. Monza: Polimetrica.

Fielding, Michael. 2007. Beyond "Voice": New Roles, Relations and Contexts in Researching with Young People. Discourse: Studies in Cultural Politics of Education 3: 301-10. [CrossRef]

Giddens, Anthony. 1984. The Constitution of Society. Cambridge: Polity Press.

Giddens, Anthony. 1992. The Transformation of Intimacy: Sexuality, Love, and Eroticism in Modern Societies. Stanford: Stanford University Press.

Gómez Espino, Juan Miguel. 2013. Two Sides of Intensive Parenting. Present and Future Dimension in Contemporary Relations between Parents and Children. Childhood 1: 22-36. [CrossRef]

Hartvigsson, Tom, and Christian Munthe. 2018. Responsibilities in Change, Modelling Parental Authority and Children's Autonomy. Available online: https://www.researchgate.net/publication/316968012 Responsibilities_in_change_modelling_parental_authority_and_children $\backslash$ T1 $\backslash$ textquoterights_autonomy (accessed on 19 October 2018).

Holland, Janet, Rachel Thomson, Sheila Henderson, Sheena McGrellis, and Sue Sharpe. 2000. ‘Catching on, Wising up and Learning from your Mistakes: Young People's Accounts of Moral Development'. The International Journal of Children's Rights 8: 271-94. [CrossRef]

Horgan, Deirdre, Catherine Forde, Shirley Martin, and Aisling Parkes. 2017. Children's Participation: Moving from the Performative to the Social. Children's Geographies 3: 274-88. [CrossRef]

Kjørholt, Anne Trine. 2007. Childhood as a Symbolic Space: Searching for Authentic Voices in the Era of Globalisation. Children's Geographies 1-2: 29-42. [CrossRef]

Labov, William. 1982. Speech actions and reactions in personal narrative. In Analyzing Discourse. Texts and Talks. Edited by Deborah Tannen. Washington: Georgetown University Press.

Lareau, Annette. 2002. Invisible Inequality: Social class and childrearing in black families and white families. American Sociological Review 5: 747-76. [CrossRef]

Lee, Nick. 2001. Childhood and Society: Growing up in an Age of Uncertainty. Buckingham: Open University Press.

Maggioni, Guido, Paola Ronfani, Maria Carmen Belloni, and Valerio Belotti. 2013. Bambini e genitori. Norme, pratiche e rappresentazioni della responsabilità. Roma: Donzelli.

Mayall, Berry. 2002. Towards a Sociology for Children: Thinking from Children's Lives. Maidenhead: Open University Press.

Moss, Peter, and Pat Petrie. 2002. From Children's Services to Children's Spaces: Public, Policy, Children and Childhood. London: Routledge-Palmer.

Olagnero, Manuela. 2006. Arrivare prima. Politiche dell'anticipo e condizione infantile. Meridiana 55: 160-75. [CrossRef]

Olagnero, Manuela. 2013. Le parole degli altri nei discorsi dei bambini. In Transizioni. Bambini e adulti nella società dell'incertezza. Edited by Maria Carmen Belloni. Roma: Carocci.

Olagnero, Manuela. 2016. Are the Kids all-right? In Well-being, Participation, Citizenship. Edited by Roberta Bosisio, Maria Carmen Belloni and Manuela Olagnero. Torino: Accademia University Press.

Olagnero, Manuela, and Dario Rei. 2011. Hearing Children, Rights, Norms and Practices. In Reflections on Children's Rights-Marginalized Identities in the Discourse of Justice. Edited by Giuseppina Cortese. Monza: Polimetrica. 
Oswell, David. 2013. The Agency of Children: From Family to global Human Rights. Cambridge: Cambridge University Press. Pocar, Valerio, and Paola Ronfani. 2008. La famiglia e il diritto. Roma-Bari: Laterza.

Prout, Alan. 2011. Taking a Step Away from Modernity: Reconsidering the New Sociology of Childhood. Global Studies of Childhood 1: 4-14. [CrossRef]

Reynaert, Didier, Maria Bourverne-de-Bie, and Stijn Vandevelde. 2009. A Review of Children's Rights Literature since the Adoption of the United Nations Convention on the Rights of the Child. Childhood 4: 518-34. [CrossRef]

Riessman, Catherine K. 2003. Narrative Methods for the Human Sciences. London and Thousands Oak: Sage.

Sarre, Sophie. 2010. Parental Regulation of Teenagers' Time: Processes and Meanings. Childhood 17: 61-75. [CrossRef]

Satta, Caterina. 2012. Bambini e Genitori: la Nuova Sociologia Dell'infanzia. Roma: Carocci.

Solberg, Anne. 1997. Negotiating Childhood: Changing Constructions of Age in Norwegian Children. In Constructing and Reconstructing Childhood. Edited by Allison James and Alan Prout. London: Routledge.

Thomas, Nigel. 2007. Towards a Theory of Children's Participation. International Journal of Children's Rights 15: 443-57. [CrossRef]

Torrioni, Paola. 2013. Genitori autorevoli o indulgenti? Processi di socializzazione familiare a confronto. In Transizioni. Bambini e adulti nella società dell'incertezza. Edited by Maria Carmen Belloni. Roma: Carocci.

Ulvik, Obbjørg, and Liv Mette Gulbrandsen. 2015. Exploring Children's Everyday Life. An Examination of Professional Practice. Journal of Nordic Psychology 3: 214-24. [CrossRef]

Vandenbroeck, Michael, and Maria Bouverne-De Bie. 2006. Children's Agency and Educational Norms. A Tensed Negotiation. Childhood 1: 127-43. [CrossRef]

Vygotsky, Lev. 1998. Infancy. In The Collected Works of L.S. Vygotsky. Edited by Robert Rieber. New York: Plenum Press, vol. 5, pp. 207-41.

Wingard, Leah. 2007. Constructing Time and Prioritizing Activities in Parent-Child Interaction. Discourse E Society 1: 75-91.

Wyness, Michael. 2015. Childhood. Cambridge: Polity Press.

Wyness, Michael. 2016. Mapping out the Field of Children's Participation. Definitions, Narratives and Disputes. In Becoming Children. Well-Being, Participation, Citizenship. Edited by Maria Carmen Belloni, Roberta Bosisio and Manuela Olagnero. Torino: Accademia University Press.

(C) 2019 by the authors. Licensee MDPI, Basel, Switzerland. This article is an open access article distributed under the terms and conditions of the Creative Commons Attribution (CC BY) license (http://creativecommons.org/licenses/by/4.0/). 